\title{
Electronic and 0ptical Properties of Nanostructures and Its Relationship with Harari Index
}

\author{
Ali Asghar Khakpoor*, Bahare Agahi Keshe \\ Department of Physics, Islamic Azad University-Central Tehran Branch (IAUCTB), Tehran, Iran \\ Email: ${ }^{*}$ Ali.khakpoor@iauctb.ac.ir, bahare.agahi@yahoo.com
}

Received 28 May 2015; accepted 12 July 2015; published 16 July 2015

Copyright (C) 2015 by authors and Scientific Research Publishing Inc.

This work is licensed under the Creative Commons Attribution International License (CC BY). http://creativecommons.org/licenses/by/4.0/ (c) (i) Open Access

\begin{abstract}
The topological index of molecular graph is a number that attributed to the molecular graph and is valid than graph isomorphism, this number can reflect the properties of the molecules. In this study, Harari index in family phenacenes was calculated with some electronic and optical properties desired for a number of elements of the family, a model for predicting the electronic and optical properties by Harari index was prepared. To offer this model using mathematical software, electronic and optical properties of phenacenes calculated and compared with the data sources.
\end{abstract}

\section{Keywords}

Nanostructures, Harari Index, Electronic and Optical Properties, Gap Energy, Phenacenes

\section{Introduction}

Around mid-century theoretical chemists and physicists noted that various features of molecular structure of organic matter can be established by examining the appropriate structure to obtain the molecular graph. These graph constants are appropriate for the purposes of the physical and chemical and called topological indices. Topological indices are real numbers in terms of graph parameters (such as the degree of vertices, distances, etc.) in the study on molecular graphs presented in chemistry and physical and chemical properties of molecules can describe [1]. One of these topological indices, Harari index was introduced in 1991 by Professor Harari [2].

Today, scientists are trying to design and provide nanoscale electronic components. Manufacture nanoscale faced with limitations in many cases virtually impossible, therefore, due to small parts in recent years has led to

${ }^{*}$ Corresponding author.

How to cite this paper: Khakpoor, A.A. and Agahi Keshe, B. (2015) Electronic and Optical Properties of Nanostructures and Its Relationship with Harari Index. Journal of Materials Science and Chemical Engineering, 3, 1-5.

http://dx.doi.org/10.4236/msce.2015.38001 
the creation of nanostructures branch in electronics [3] [4].

Molecular electronic also called moltronic is a branch of nano-electronics that study the use of small groups of molecules in nano dimensions. Phenacenes are organic molecules that are highly regarded in molecular electronics and nanoscale. Because of the important electronic properties of the family, many research and studies have been done on them [5]. But in the molecules that the number of rings is more than six rings, measuring the electronic and optical properties needed to spend a long time and high cost. In these circumstances, there is a model for predicting the electronic and optical properties will be particularly important [6].

\section{Definitions}

Graph in mathematic is non-empty set of objects called vertices $(V)$ are the vertices by lines called edges $(E)$ connected and it show as $G=G(V, E)$. A molecular graph is simple graph, which is mainly composed of atoms of one molecule and the bonds between the atoms, are graph edges. In chemical graphs hydrogen atoms have been removed and will be ignored and the degree of each vertex is maximum 4 and all bonds between atoms are considered single.

Topological indexes are defined on the basis of graph theory [7] [8].

One of these topological indices, Harari index is defined by:

$$
H=\left(\frac{1}{2}\right) \sum_{i=j}^{N} \sum_{j \neq i}^{N} d_{i j}^{-1}
$$

where $d_{i j}$ is elements of the distance matrix.

\section{Methodology}

The purpose of this paper is to obtain a simple model based on graph theory to predict optical and electronic properties of phenacenes.

Chemical formula phenacenes family is $\mathrm{C}_{4 n+2} \mathrm{H}_{2 n+4}$ with the $n \geq 2$. For example, the Harari index for $\mathrm{C}_{10} \mathrm{H}_{8}$ molecules is calculated. In Figure 1. The simple graph of the molecule is drawn.

According to Figure 1, the inverse matrix of $\mathrm{C}_{10} \mathrm{H}_{8}$ calculated in Table 1. Is as follows:

Using the Equation (1) Harari index for molecules $\mathrm{C}_{10} \mathrm{H}_{8}$ number 23.9 obtained $(H=23.9)$.

Harary index molecules $\mathrm{C}_{4 n+2} \mathrm{H}_{2 n+4}$ to $n=7$ as well as the calculated and results in Table 2 shown.

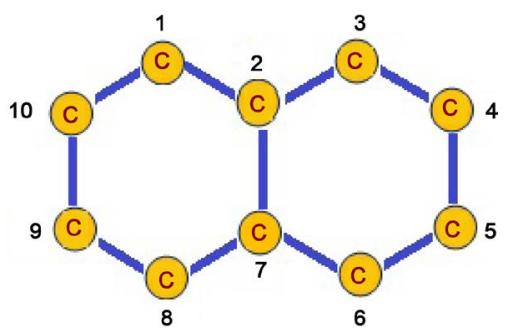

Figure 1. The simple graph of the molecule $\mathrm{C}_{10} \mathrm{H}_{8}$.

Table 1. The inverse matrix of $\mathrm{C}_{10} \mathrm{H}_{8}$.

$d=\left(\begin{array}{cccccccccc}0 & 1 & 0.5 & 0.33 & 0.25 & 0.33 & 0.5 & 0.33 & 0.5 & 1 \\ 1 & 0 & 1 & 0.5 & 0.33 & 0.5 & 1 & 0.5 & 0.33 & 0.5 \\ 0.5 & 1 & 0 & 1 & 0.5 & 0.33 & 0.5 & 0.33 & 0.25 & 0.33 \\ 0.33 & 0.5 & 1 & 0 & 1 & 0.5 & 0.33 & 0.25 & 0.2 & 0.25 \\ 0.25 & 0.33 & 0.5 & 1 & 0 & 1 & 0.5 & 0.33 & 0.25 & 0.2 \\ 0.33 & 0.5 & 0.33 & 0.5 & 1 & 0 & 1 & 0.5 & 0.33 & 0.25 \\ 0.5 & 1 & 0.5 & 0.33 & 0.5 & 1 & 0 & 1 & 0.5 & 0.33 \\ 0.33 & 0.5 & 0.33 & 0.25 & 0.33 & 0.5 & 1 & 0 & 1 & 0.5 \\ 0.5 & 0.33 & 0.25 & 0.2 & 0.25 & 0.33 & 0.5 & 1 & 0 & 1 \\ 1 & 0.5 & 0.33 & 0.25 & 0.2 & 0.25 & 0.33 & 0.5 & 1 & 0\end{array}\right)$


Table 2. Harary index molecules $\mathrm{C}_{4 \mathrm{n}+2} \mathrm{H}_{2 \mathrm{n}+4}$ to $\mathrm{n}=7$.

\begin{tabular}{|c|c|c|c|}
\hline Chemical Formula & Simple Graph & IUPAC Name & $\mathbf{H}$ \\
\hline $\mathrm{C}_{10} \mathrm{H}_{8}$ & & Naphthalene & 23.9 \\
\hline $\mathrm{C}_{14} \mathrm{H}_{10}$ & & Phenanthrene & 41.1 \\
\hline $\mathrm{C}_{18} \mathrm{H}_{12}$ & & Chrysene & 60.7 \\
\hline $\mathrm{C}_{22} \mathrm{H}_{14}$ & & Picene & 82.1 \\
\hline $\mathrm{C}_{26} \mathrm{H}_{16}$ & & Fulminene & 104.9 \\
\hline $\mathrm{C}_{30} \mathrm{H}_{18}$ & & 7-phenacene & 129 \\
\hline
\end{tabular}

\section{Results}

Some electronic and physical properties of phenacenes family $\left(\mathrm{C}_{4 n+2} \mathrm{H}_{2 n+4}\right)$, the Ionization Energy, Bind Energy, Gap Energy and Electron Affinity Energy using software (Gaussian 09) was calculated and experimental data in the valid literature was compared. The results in Table 3. Had shown [6] [9] [10].

Using Table 2 and Table 3 data changes plot $E_{\text {gap }}$ and $E_{\text {bind }}$ in Harari index $(H)$ in the Figure 2 and Figure 3 is drawn:

As the Figure 2 and Figure 3 can be predicted $E_{\text {gap }}$ and $E_{\text {bind }}$ in phenacenes family by the Harari index is possible and this prediction is very accurate, so that $E_{\text {bind }}$ and $E_{\text {gap }}$ carefully before $\mathrm{R}^{2}=1$ predicted.

Figure 2 and Figure 3 can be expected to provide the following relationships:

$$
\begin{aligned}
& E_{\text {gap }}=5 \times 10^{-9} H^{5}-2 \times 10^{-6} H^{4}+0.0003 H^{3}-0.018 H^{2}+0.5209 H-0.9661 \\
& E_{\text {bind }}=2 \times 10^{-9} H^{5}-7 \times 10^{-7} H^{4}+1 \times 10^{-4} H^{3}-0.0065 H^{2}+0.1776 H+2.221
\end{aligned}
$$

Also in the Figures Figure 4 and Figure 5 changes diagram in both property Ionization Energy and Electron Affinity Energy of phenacenes family in term of Harari index $(H)$ plotted.

Prediction of $E_{\text {Ionization }} E_{\text {Affinity }}$ by the Harari index Figures Figure 4 and Figure 5 is associated with very high accuracy, so that predicted $E_{\text {Ionization }}$ and $E_{\text {Affinity }}$ will carefully $R^{2}=1$ is possible in the family phenacenes. The Ionization Energy ( $\left.E_{\text {Ionization }}\right)$ and Electron Affinity Energy ( $\left.E_{\text {Affinity }}\right) \mathrm{C}_{4 n+2} \mathrm{H}_{2 n+4}$ molecules can be predicted by the following relationship:

$$
\begin{aligned}
& E_{\text {Affinity }}=-2 \times 10^{-9} H^{5}+9 \times 10^{-7} H^{4}-0.0001 H^{3}+0.0084 H^{2}-0.2348 H+2.0301 \\
& E_{\text {Ionization }}=2 \times 10^{-9} H^{5}-8 \times 10^{-7} H^{4}+0.0001 H^{3}-0.0073 H^{2}+0.1957 H+5.9807
\end{aligned}
$$

\section{Conclusions}

As Figures 2-5 shown using the Harari topological index, some electronic and optical properties of phenacenes family are given by $\mathrm{C}_{4 n+2} \mathrm{H}_{2 n+4}$ predict with great accuracy.

The success of the predicted energy gap $E_{\text {gap }}$, bind energy $E_{\text {bind }}$, ionization energy $E_{\text {Ionization }}$ and affinity electron energy $E_{\text {Affinity }}$ with Relations (2)-(5) is possible. 


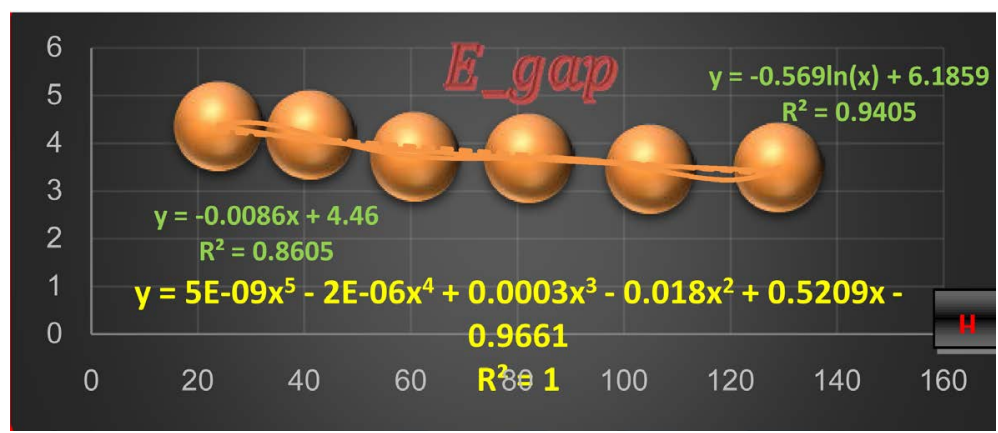

Figure 2. Changes plot $E_{\text {gap }}$ in Harari index $(H)$ for phenacenes family.

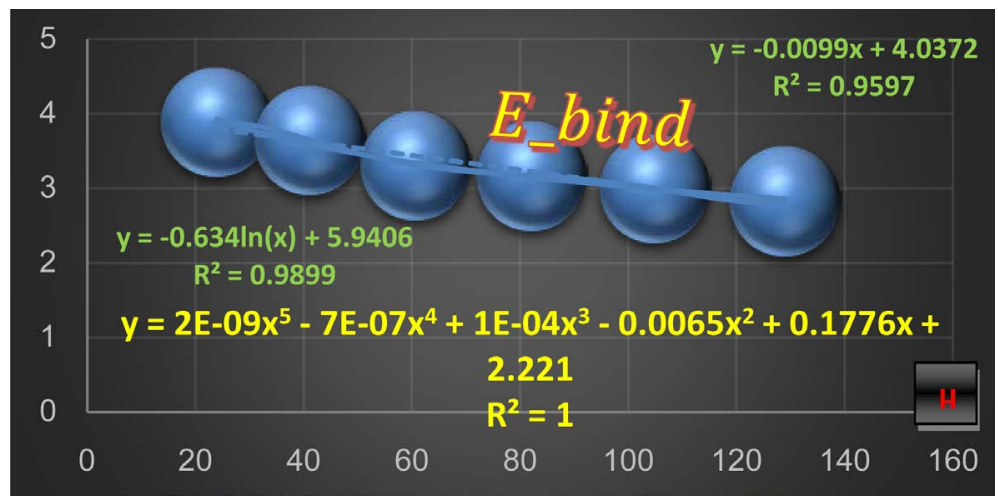

Figure 3. Changes plot $E_{\text {bind }}$ in Harari index $(H)$ for phenacenes family.

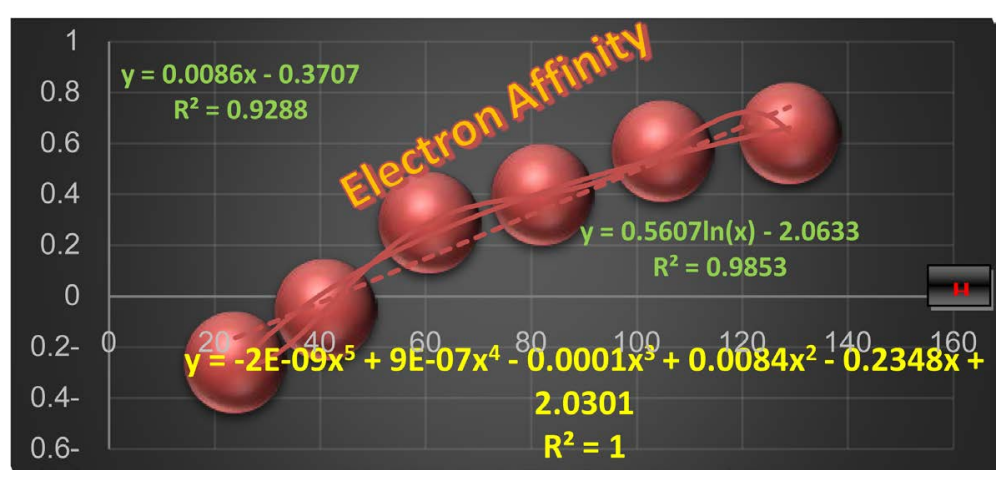

Figure 4. Changes plot $E_{\text {Affinity }}$ in Harari index $(H)$ for $\mathrm{C}_{4 n+2} \mathrm{H}_{2 n+4}$.

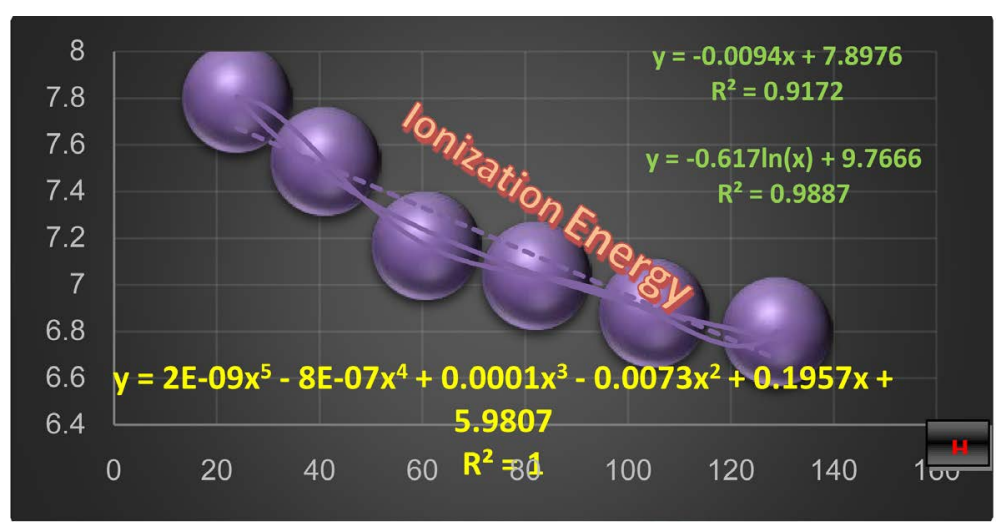

Figure 5. Changes plot $E_{\text {Ionization }}$ in Harari index $(H)$ for $\mathrm{C}_{4 n+2} \mathrm{H}_{2 n+4}$. 
Table 3. $E_{\text {Affinity }}, E_{\text {Gap }}, E_{\text {Ionization }}$ and $E_{\text {Bind }}$ of phenacenes family.

\begin{tabular}{cccccc}
\hline Chemical Formula & IUPAC Name & $\boldsymbol{E}_{\text {Bind }}(\mathbf{e v})$ & $\boldsymbol{E}_{\text {Ionization }}(\mathbf{e v})$ & $\boldsymbol{E}_{\text {Gap }}(\mathbf{e v})$ & $\boldsymbol{E}_{\text {Affinity }}(\mathbf{e v})$ \\
\hline $\mathrm{C}_{10} \mathrm{H}_{8}$ & Naphthalene & 3.89 & 7.8 & 4.36 & -0.26 \\
$\mathrm{C}_{14} \mathrm{H}_{10}$ & Phenanthrene & 3.65 & 7.53 & 4.19 & -0.05 \\
$\mathrm{C}_{18} \mathrm{H}_{12}$ & Chrysene & 3.31 & 7.17 & 3.73 & 0.29 \\
$\mathrm{C}_{22} \mathrm{H}_{14}$ & Picene & 3.17 & 7.04 & 3.70 & 0.40 \\
$\mathrm{C}_{26} \mathrm{H}_{16}$ & Fulminene & 3 & 6.88 & 3.47 & 0.57 \\
$\mathrm{C}_{30} \mathrm{H}_{18}$ & 7-phenacene & 2.83 & 6.80 & 3.50 & 0.64 \\
\hline
\end{tabular}

\section{Acknowledgements}

We would like to thank Islamic Azad University Central Tehran Branch (IAUCTB) for helpful protections. Also we acknowledge all those who have helped us with their support and cooperation in conducting this study.

\section{References}

[1] Bonchev, D. (1983) Information Theoric for Characterization of Chemical Structures. Reserch Studies Press, Latchworth.

[2] Plavsic, D., Nikolic, S., Trinajstic, N. and Mihalic, Z. (1993) On the Harary İndex for the Characterization of Chemical Graphs. Journal of Mathematical Chemistry, 12, 235-250. http://dx.doi.org/10.1007/BF01164638

[3] Pérez-Jiménez, A.J. and Sancho-Garca, J.C. (2009) Conductance Enhancement in Nanographene-Gold Junctions by Molecular $\pi$-Stacking. Journal of the American Chemical Society, 131, 14857-14867. http://dx.doi.org/10.1021/ja904372d

[4] Sancho-García, J.C. and Pérez-Jiménez, A.J. (2009) Charge-Transport Properties of Prototype Molecular Materials for Organic Electronics Based on Graphene Nanoribbons. Physical Chemistry Chemical Physics, 11, 2741-2746. http://dx.doi.org/10.1039/b821748c

[5] Jiang, D. and Dai, S. (2008) Circumacenes versus Periacenes: HOMO-LUMO Gap and Transition from Nonmagnetic to Magnetic Ground State with Size. Chemical Physics Letters, 466, 72-75. http://dx.doi.org/10.1016/j.cplett.2008.10.022

[6] Lias, S. (2005) Ionization Energy Evaluation. İn: Linstrom, P.J. and Mallard, W.G., Eds., NIST Chemistry WebBook, NIST Standard Reference Database Number 69, National Institute of Standards and Technology, Gaithersburg. http://webbook.nist.gov

[7] Trinajstic, N. (1992) Chemical Graph Theory. 2nd Edition, CRC Press, Boca Raton.

[8] Ezra, G.S. (1982) Lecture Notes in Chemistry. Springer, Germany.

[9] Kadantsev, E.S., Stott, M.J. and Rubio, A. (2006) Electronic Structure and Excitations in Oligoacenes from $a b$ Initio Calculations. The Journal of Chemical Physics, 124, 134901. http://dx.doi.org/10.1063/1.2186999

[10] Malloci, G., Mulas, G., Cappellini, G. and Joblin, C. (2007) Time-Dependent Density Functional Study of the Electronic Spectra of Oligoacenes in the Charge States $-1,0,+1$, and +2 . Chemical Physics, 340, 43-58. http://dx.doi.org/10.1016/j.chemphys.2007.07.046 